\title{
Psicología de los procesos cognitivos y la resolución de problemas en educandos con discapacidad intelectual y del desarrollo
}

\author{
Psychology of cognitive processes and problem solving in students with intellectual and \\ developmental disabilities
}
Psicologia dos processos cognitivos e resolução de problemas em alunos com deficiência intelectual e de desenvolvimento

\section{Thaiz Arráez}

thaizarraez@gmail.com

https://orcid.org/0000-0003-3430-9359

Universidad Pedagógica Experimental Libertador, Caracas, Venezuela
Recibido: noviembre 2019

Revisado: noviembre 2019

Aceptado: diciembre 2019

Publicado: enero 2020

\section{RESUMEN}

El presente estudio tuvo como propósito analizar un conjunto de proposiciones de valor teóricoconceptual de una cantidad de autores sobre la naturaleza del acto de pensar y resolver problemas en educandos con discapacidad intelectual y del desarrollo bajo la visión de la psicología de los procesos cognitivos. Desde el punto de vista metodológico, se enmarcó en una investigación documental de carácter monográfico. El método usado fue deductivo, empleando como técnica el análisis de contenido a través del programa computacional ATLAS-ti. Los resultados apuntan hacia una nueva concepción de la práctica educativa. Se concluye con la valorización de las diferencias desde las potencialidades de cada persona con discapacidad intelectual en el marco de la formación y atención pedagógica inclusiva.

Palabras clave: Discapacidad intelectual; acto de pensar; resolver problemas; procesos cognitivosn
ABSTRACT

The present study aimed to analyze a set of theoretical-conceptual value propositions from a number of authors on the nature of the act of thinking and solving problems in students with intellectual and developmental disabilities under the vision of the psychology of cognitive processes. From the methodological point of view, it was framed in a documentary investigation of a monographic nature. The method used was deductive, using content analysis as a technique through the ATLASti computer program. The results point to a new conception of educational practice. It concludes with the valuation of the differences from the potentialities of each person with intellectual disabilities in the framework of inclusive pedagogical training and care.

Key words:

Intellectual disability; act of thinking; solve problems; cognitive processes

\section{RESUMO}

O presente estudo teve como objetivo analisar um conjunto de proposições de valor teóricoconceituais de diversos autores sobre a natureza do ato de pensar e resolver problemas em alunos com deficiência intelectual e de desenvolvimento sob a ótica da psicologia dos processos cognitivos. Do ponto de vista metodológico, enquadrou-se numa investigação documental de natureza monográfica. O método utilizado foi o dedutivo, tendo como técnica a análise de conteúdo por meio do programa ATLAS-ti. Os resultados apontam para uma nova concepção da prática educativa. Conclui com a apreciação das diferenças das potencialidades de cada pessoa com deficiência intelectual no quadro de uma formação e assistência pedagógica inclusiva.

Palavras-chave:

Deficiência intelectual; ato de pensar; resolver problemas; processos cognitivos 


\section{INTRODUCCIÓN}

El pensamiento está estructurado de manera coherente, congruente y consistente porque la construcción del mismo se llevó a cabo teniendo como factor metodológico principios inherentes a la lógica, espacio teórico-conceptual que los estudiosos han terminado por calificarla junto a la matemática como ciencia formal al mismo tiempo que llega a considerar que lo descrito, analizado e interpretado son las respuestas acertadas, que parte de un conjunto de habilidades y destrezas de orden cognitivo y emocional que lo colocan pensante o cognoscente en la capacidad de aprender teniendo como factor o denominador común la resolución de problemas.

Polya (1962), plantea que la capacidad de superar una dificultad, de seguir un camino indirecto cuando el directo no aparece, es lo que coloca al animal inteligente sobre el tope, lo que coloca al hombre por encima de los animales más inteligentes y a los hombres de talento por encima de sus compañeros, los otros hombres.

En este mismo orden de ideas, Simon (1978), establece que un individuo se enfrenta a un problema, cuando ha aceptado una tarea pero no sabe cómo la va a realizar. El hecho de haber aceptado la tarea implica que la persona tiene algún criterio para determinar el momento en que la tarea se ha completado con éxito. Greeno (1980), sugiere que un requisito fundamental para que se presente un problema es que en la representación mental del sujeto haya "lagunas o inconsistencias", en caso contrario no se puede hablar de un problema.

Los procesos de solución de problemas están íntimamente relacionados con el aprendizaje y la activación de los procesos básicos de pensamiento, hasta el punto de que es difícil encontrar aspectos dentro de lo que Mayer (1986) llama la "capacidad de pensar" que no se relacionen con la capacidad de resolver problemas".

El propósito de este trabajo es investigar, a través de un estudio documental monográfico, los planteamientos más resaltantes presentados por algunos autores sobre

¿Cuáles procesos cognitivos intervienen en los educandos con discapacidad intelectual y del desarrollo para resolver problemas? y ¿Cómo resuelven problemas de la vida cotidiana y laboral?

En cuanto al objetivo general se persigue, analizar un conjunto de proposiciones de valor teórico-conceptual de una variedad de autores sobre la resolución de problemas en educandos con discapacidad intelectual y del desarrollo bajo la psicología de los procesos cognitivos.

En relación a los objetivos específicos, se pretende: (a) Identificar la estructura conceptual que subyace en las obras estudiadas como elemento constituyente para la resolución de problemas en personas con discapacidad intelectual y del desarrollo bajo la psicología de los procesos cognitivos (b) Caracterizar los constructos en los que confluyen los autores estudiados en cuanto a la resolución de problemas en el educando con discapacidad intelectual y del desarrollo y (c) Integrar los elementos teóricos de las obras presentadas con los principios fundamentales para la resolución de problemas en el educando con discapacidad intelectual y del desarrollo.

Específicamente, este estudio puede ofrecer su contribución en el área de los procesos de aprendizaje de las personas con discapacidad intelectual y del desarrollo, desde varios ángulos: (a) desde el punto de vista teórico, aborda un tema poco investigado en Latinoamérica; (b) desde el punto de vista metodológico reviste un intento de reunir evidencias sobre la base de documentos originales y el análisis exhaustivo de ellos; para entender cómo la intervención en 
los procesos cognitivos favorecen la resolución de problemas en educandos con discapacidad intelectual y del desarrollo (c) desde el punto de vista práctico, constituye una oportunidad para que, sobre la base de los resultados se den orientaciones y desarrollen metodologías para la atención educativa integral de las personas con esta condición. En este sentido, se espera que este trabajo pueda aportar elementos de reflexión a docentes y estudiantes de educación especial en la especialidad de discapacidad intelectual y del desarrollo en diversos contextos universitarios.

\section{Referentes teóricos}

Las investigaciones sobre el proceso cognitivos en la resolución de problemas de la vida cotidiana y laboral se han visto influenciado por grandes cambios desde su origen, ha pasado por el paradigma conductista hasta la psicología de los procesos cognitivos.

Ahora bien, el término de discapacidad intelectual se deriva del constructo general de discapacidad, que en los últimos veinte años se ha modificado bajo una perspectiva socioecológica, con énfasis en la interacción de la persona con su entorno, así como los apoyos sistemáticos e individualizados que mejoran el funcionamiento humano. La construcción social de la conceptualización de discapacidad intelectual estuvo influida por el enfoque multidimensional del funcionamiento humano propuesto por la Clasificación Internacional del Funcionamiento, la Discapacidad y la Salud de la Organización Mundial de la Salud (OMS, 2001) que define la discapacidad como

...el funcionamiento humano es un término genérico que alude a todas las actividades vitales de un individuo y abarca estructuras y funciones corporales, actividades personales y participación. Las limitaciones en el funcionamiento se denominan discapacidad que puede derivar de un problema o varios en las estructuras y funciones corporales y en las actividades personales ( $p: 23)$.

Desde esta perspectiva, se asume la definición establecida por la Asociación Americana de Discapacidades Intelectuales y del Desarrollo (AAIDD), organización fundada en el año 1876, la cual lideriza la comprensión, definición, clasificación y sistemas de apoyo del constructo actualmente designado como discapacidad intelectualen la undécima edición del manual,en donde la delimita como:

\begin{abstract}
... una discapacidad caracterizada por limitaciones significativas tanto en el funcionamiento intelectual como en la conducta adaptativa tal y como se ha manifestado en habilidades adaptativas conceptuales, sociales y prácticas. Esta discapacidad comienza antes de los 18 años. (AAIDD, 2011, p. 31).
\end{abstract}

Lo que caracteriza a las personas con Discapacidad Intelectual y del desarrollo son sus diferencias en el funcionamiento intelectual, cuyas funciones se encuentran comprometidas en menor o mayor grado haciéndoles funcionar diferente, al resto de las personas de su mismo grupo etáreo, tanto en su relación con el entorno, como en la adquisición de conocimientos.

Por su parte, Zazzo (1973), califica el desarrollo intelectual de las Personas con Discapacidad Intelectual como "heterocrónico", es decir, que presenta diferencias tanto cuantitativas como cualitativas, entre unos procesos y otros, en un momento dado. Estas diferencias no son constantes, sino que varía a lo largo del proceso de desarrollo individual, dependiendo de los efectos socio-ambientales, entre ellos la atención pedagógica recibida, lo que implica la aceptación 
de la posible " compensación " de la condición de discapacidad intelectual. Esto significa que, a través de la intervención educativa integral, que considere las diferencias individuales y favorezca el desarrollo máximo de diferencias cognitivas de la persona con, independientemente del compromiso de las mismas, sus potencialidades pueden ser desarrolladas y sus déficits compensados.

Por otra parte, las diferencias a nivel cognitivo van a estar determinadas por diversos factores relacionados con la etiología de esta condición como son: tipo de agente nocivo (a nivel genético, intrauterino, perinatal, entre otras), tiempo en que ese agente actúa, intensidad y extensión de la lesión y condiciones, externas, físicas y sociales del desarrollo del niño. Asimismo, estas diferencias se reflejan en otras áreas como son: la psicomotricidad, la comunicación, las habilidades sociales, las habilidades académicas y emocionales, las cuales pueden resultar afectadas en mayor o menor grado, lo que hace a esta población heterogénea.

La psicología de los procesos cognitivos se refiere, según Prieto y Arnáiz (1992), al potencial que tiene el estudiante para construir su propio aprendizaje; así como también en la interpretación que hace el educando sobre los contenidos y técnicas que debe manejar para apropiarse del conocimiento, a la adaptación de éstos a sus esquemas mentales y a la relevancia de distinguir los pasos para resolver problemas de la vida cotidiana.

Es por esto, que la psicología de los procesos cognitivos, tal como acotan Beltrán, Bermejo, Prieto y Vence (1993) se encuadra en el movimiento conocido como "enseñar a pensar" ( $p$ 20). El punto central es que promueve que el pensamiento es un proceso a introducir en las diversas áreas del conocimiento. Esto se traduce en enseñar las disciplinas escolares de manera que se potencie la elaboración y la autorregulación del aprendizaje.
Desde la perspectiva cognitiva, Simon (1980), plantea que la solución satisfactoria y eficaz de problemas, desde el más elemental al más complejo e independientemente de la naturaleza, requieren esencialmente el uso de las mismas destrezas de procesamiento de información. Cada una de estas actividades requiere una interacción entre el conocimiento base, la organización de la información de entrada, el uso de estrategias de procesamiento y la realización de actividades orientadas al logro de una meta.

En este mismo orden de ideas, Andre (1986), plantea que para resolver problemas, el sujeto debe representar la tarea en su memoria de alguna forma. Esta representación forma el espacio del problema e incluye descripciones de objetos, de la situación inicial y de la meta, y operaciones que producen cambios en la situación.

El autor antes citado, señala que la representación que una persona emplea al resolver un problema puede facilitar o inhibir la solución. Menciona algunas diferencias entre los novatos y expertos entre las cuales resalta, la habilidad de los expertos en clasificar los problemas en tipos, mientras que los novatos tratan los problemas de manera individual. En este caso, la información previa que tiene el experto facilita la representación.

De acuerdo con Simon (1978), los espacios del problema o representaciones están constituidos por nódulos. Cada nódulo representa un posible estado del conocimiento del sujeto en un momento determinado. El espacio problema, el sujeto lo va construyendo a medida que se acerca en la búsqueda de la solución. Para progresar de un nódulo a otro, el sujeto debe seleccionar un operador que ejecute el cambio. Es importante destacar que en algunos de los casos se hace necesario devolverse a algún nódulo anterior para seguir una mejor dirección. 
Otro aspecto importante, es el proceso de búsqueda que conceptualiza Simon (1978) como aquellas operaciones mentales que el solucionador de problemas emplea para pensar acerca de la representación de las metas y los datos para tratar de transformar estos en las metas con el fin de alcanzar la solución.

En cuanto a los procesos cognitivos que intervienen para resolver problemas en las personas con discapacidad intelectual se ha pretendido explicar desde dos teorías diferentes, la teoría evolutiva y la teoría estructural. La teoría evolutiva sostiene que las personas con discapacidad intelectual pasan por las mismas etapas de desarrollo cognitivo como cualquier persona normal, pero lo hacen más lentamente y no consiguen alcanzar el mismo nivel final que sería el de las operaciones formales. El mejor exponente de este enfoque lo ofrece la teoría del desarrollo cognitivo de Piaget y su defensor inicial es Zigler (1969).

En esta aproximación se destacan los procesos cognitivos y se adjudica que son modificables a través de entrenamiento continuo. Por su parte, la teoría estructural sostiene que las personas con discapacidad intelectual se caracterizan no tanto por un desarrollo retrasado, sino por un déficit específico que afectarían especialmente al sistema cognitivo de la memoria.

El autor Pozo (2016) plantea que el aprendizaje es un cambio relativamente permanente $y$ transferible en los conocimientos, habilidades, actitudes, emociones, creencias de una persona como consecuencia de su practicas sociales mediadas por ciertos dispositivos culturales y la influencia de la memoria.

En esta línea, Ellis (1963) sostiene que las personas con discapacidad intelectual presentan un déficit particular en su huella de memoria para lograr el aprendizaje, por lo que la información se debilita más rápidamente en las distintas memorias.
Luria (1963) por su parte sostiene que las personas con discapacidad intelectual tienen un déficit muy particular en el uso de la mediación verbal y del lenguaje interno para orientar el pensamiento y la conducta.

Un aspecto importante a considerar, es la representación mental, que consiste según Rimoldi (1996) en la creación de imágenes, símbolos o representaciones para transformar la información presentada es una forma más fácil de almacenar en el sistema de memoria, e incluye la identificación de las metas y los datos.

Miranda y Gil (2002), plantean que es importante resaltar que al estudiar las estrategias empleadas por los niños de temprana edad para resolver problemas, es indispensable observar los mapas que desarrollan en sus juegos. El descubrimiento o innovación son formas adecuadas de representación que facilita el progreso de las estructuras más complejas que requiere el proceso educativo. Podría afirmarse que la evolución del conocimiento requiere de representaciones mentales en el educando que faciliten la comprensión y apropiarse de un sistema de relaciones y operaciones que existen entre los componentes del problema que se intenta resolver.

Jintendra, Hoff y Beck (1999) expresan que las técnicas de representación como los esquemas permiten una traducción efectiva o una interpretación de la información del texto median la resolución del problema. Al enseñar a los estudiantes a utilizar las representaciones para resolver problemas, su rendimiento y el mantenimiento de los conocimientos son mejores que los estudiantes que reciben instrucción básica a través de los libros de texto.

\section{MÉTODO}

La investigación es un proceso que permite descubrir nuevos hechos o datos, basándose en 
procedimientos sistemáticos y científicos, para obtener información relevante sobre un problema que se desea resolver en cualquier campo del conocimiento humano.

Este estudio, se enmarcó en una investigación documental, de carácter monográfico, Balestrini (2003) la define como una de las alternativas de la investigación científica donde se sugiere la incorporación de un esquema de investigación, en el cual la recolección de información se encuentra vinculada a la delimitación de un diseño bibliográfico.

La población estuvo conformada por un conjunto de autores que se organizaron de acuerdo a los siguientes aspectos: (a) enfoque cognitivo en la resolución de problemas, (b) la resolución de problemas aritméticos en educandos con retardo mental y (c) estrategias de representación.

La muestra teórica seleccionada para este estudio respondió a tres (3) criterios fundamentales: en función de los objetivos de la investigación, en base a los modelos trabajados y de manera más específica a las teorías sobre procesamiento de la información y de los nódulos de representación.

En el Cuadro 1, se puede apreciar la muestra seleccionada, considerando los aspectos inherentes a toda referencia bibliográfica.

Cuadro 1. Muestra seleccionada para la investigación.

\begin{tabular}{|c|c|c|c|}
\hline Categorías & Autores & Año & Obras \\
\hline & Simon, $\mathrm{H}$ & 1980 & $\begin{array}{l}\text { Simon, H. A. (1980) Problem solving in education. } \\
\text { En D.T. Tuma \& F. Reif (Comp.) Problem solving and } \\
\text { education: Issues in Teaching and research. (pp. 81- } \\
\text { 96). Hillsdale; N.J.: Erlbaum. }\end{array}$ \\
\hline
\end{tabular}

Resolución de problemas bajo un Andre, $\mathrm{T}$

enfoque cognitivo

Baroody, A

Ginsburg, $\mathrm{H}$

Beltrán J., Bermejo, V., Prieto, M., \& Vence, D.

Resolución de problemas bajo un enfoque cognitivo
Bermejo \& Rodríguez

1994

Carpenter, T. P; Empson, S. B., \& Jacobs, $\mathrm{V}$
1986

1987

1989

Andre, T. (1986) Problem solving and Education. En G.D. Phyre \& T. Andre (Comp.).Cognitive classroom Learning. Understanding Thinking and problem solving. New York: Amedemic Press.

Baroody, A. (1987). Children's mathematical Thinking. New York: Theachers College. Columbia University

Ginsburg, H. (1989). Prólogo. En A. Baroody (Comp.) El pensamiento matemático en los niños .Madrid: Visor: Libros.

Beltrán J., Bermejo, V., Prieto, M., \& Vence, D. (1993). Intervención Psicopedagógica. Madrid: Ediciones Pirámide. S. A España.

Bermejo, V. \& Rodríguez, P. (1994). Competencia conceptual y de procedimiento: comprensión de la propiedad conmutativa de la adición y estrategias de solución. Estudios de Psicología.51, 3-21

1995 Carpenter, T. P., Empson, S. B., \& Jacobs, V. (1995, Noviembre). Integración de la investigación cognitiva con la investigación en el aula: ejemplos de instrucción matemática innovadora. Congreso de Psicología y Educación, Madrid España. 


\begin{tabular}{llll}
\hline Categorías & Añores & Obras \\
\hline Puente & 1998 & $\begin{array}{l}\text { Puente, A. (1993). Modelos mentales y habilidades } \\
\text { en la solución de problemas aritméticos verbales. } \\
\text { Revista de Psicología General y Aplicada.46. (2), } \\
\text { 149-160. }\end{array}$ \\
$\begin{array}{lll}\text { Sterneberg, R \& } \\
\text { Detterman, D }\end{array}$ & $\begin{array}{l}\text { Sternberg, R., \& Detterman, D. (1992). ¿Qué es la } \\
\text { Inteligencia? Enfoque actual de su naturaleza y } \\
\text { definición. (2a ed.). Madrid: Pirámide. }\end{array}$
\end{tabular}

Rimoldi, $\mathrm{H}$

1996

Pensamiento y resolución de problemas

Miranda, C; Arlandis, P \& Soriano, $M$
Jintendra, A Hoff, $\mathrm{K}$ \&Beck, M

Miranda, C \& Gil, M

AAIDD, 2011

Proceso de resolución de problemas en el educando

Discapacidad intelectual
Hale, C \& Borkowski, J

Benedet, J
Gerard, G
Rimoldi, H. (1996). Estructuras e imágenes en la solución de problemas. Revista de Psicología General y Aplicada, 30, (3), 285-296.

1997 Miranda, A.; Arlandis, P \& Soriano, M. (1997). Instrucción en estrategias y entrenamiento atribucional: efectos sobre la resolución de problemas y el autoconcepto de los estudiantes con dificultades de aprendizaje. Infancia y Aprendizaje, $80,37-52$

1999 Jintendra, A., Hoff, K \& Beck, M (1999). Teaching middle scholl students with learning disabilities to solve word problems using a schema-based approach. Remedial and Special Education, 20, 50 64.

2002 Miranda, C, \& Gil, M; (2002). Las dificultades de Aprendizaje de las matemáticas en educación primaria: el cálculo. En Aplicaciones de Intervención Psicopedagógica. Coordinador Garcia, J. Ediciones Pirámide.

Asociación Americana de Discapacidades Intelectuales y del Desarrollo (AAIDD) (2011). Discapacidad intelectual. Definición, clasificación y sistemas de apoyo. Traducción de Miguel Ángel Verdugo Alonso. Undécima Edición. Psicología Alianza Editorial. Madrid: España.

Gerard, G. (1990). Las estrategias que los estudiantes discapacitados se ayudan para aprender a solucionar los problemas verbales de matemáticas. Preventing School Faulure, Fall, 35.

Hale, C\& Borkowski, J. (1991). Attention, memory and cognition. En J. Matson, y J Mulick (Eds): Handbook of Mental Retardation. New York: Pergamon Press

Benedet, J. (1991). Procesos cognitivos en la deficiencia mental. Concepto, evaluación y bases para la intervención. Madrid: Pirámide. 


\section{RESULTADOS}

En este apartado se presentan las evidencias y las ideas resumidas de las fuentes analizadas para esta investigación.

El análisis e interpretación de los datos se realizó a través del recurso informático Atlasti versión 7.0. Esta confrontación se hizo con los aportes teóricos expresados por los autores estudiados en esta investigación.

En relación al objetivo uno, el cual tenía como propósito, identificar la estructura conceptual que subyace en las obras estudiadas como elemento constituyente para la resolución de problemas con discapacidad intelectual, se encontraron resultados orientados a la comprensión de los procesos estudiados en el marco de la estructuración del pensamiento como proceso mental que cualifica a cada persona.

En las próximas páginas se muestra el Gráfico correspondiente a la red semántica elaborado por la autora sobre la resolución de problemas y el pensamiento bajo la psicología de los procesos cognitivos. 


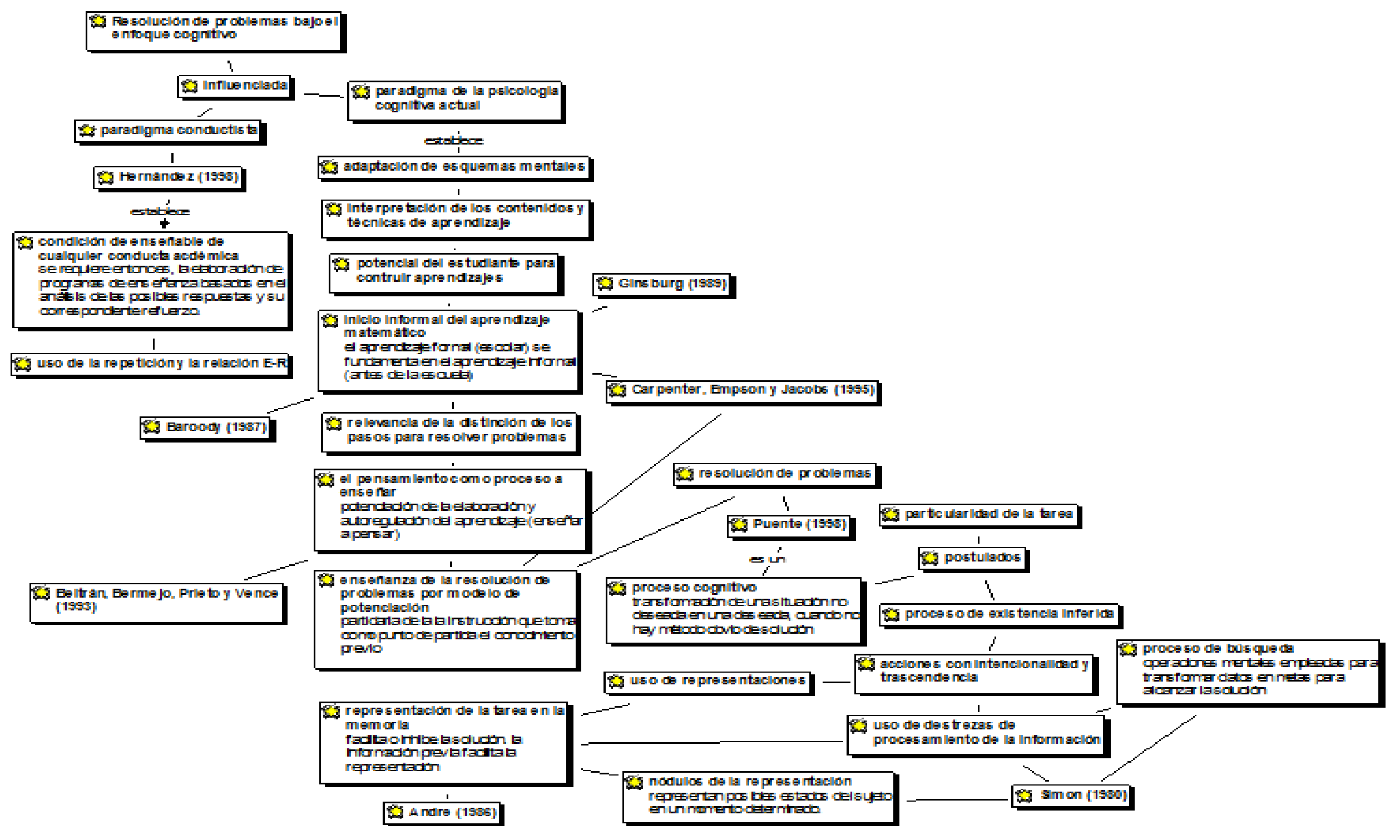

Gráfico 1. Red Semántica elaborado por la autora con las obras sobre resolución de problemas bajo la psicología de los procesos cognitivos 
En relación al segundo objetivo de la investigación orientado a caracterizar el proceso de resolución de problemas en educandos con discapacidad intelectual y del desarrollo a partir de los planteamientos de los autores estudiados, se ha de considerar lo expresado en el Gráfico 2.

Se muestra la postura de los autores Benedit (1991) y Gallagher (2001), los cuales plantean las dificultades en los procesos de pensamiento de los educandos con discapacidad intelectual para resolver problemas de la vida cotidiana.

Estas características de pensamiento radican en que retienen la información por un tiempo muy corto en la memoria de trabajo, por lo que se le conflictúa la generalización y la transferencia de lo aprendido a otras situaciones.

Presentan apuro para discriminar la información relevante y la irrelevante, se les dificulta la planificación de la información, igualmente presentan déficit en la toma de decisiones, ausencia del uso espontáneo de estrategias de almacenamiento e inconveniente para recordar la información.

La explicación dada por los autores sobre los déficits presentados se debe posiblemente a problemas en la memoria de trabajo, a problemas atencionales o a una combinación de ambos factores. Otra explicación, es que al acceder a estos conceptos no es solamente cuestión de aprendizaje, sino que está íntimamente ligado a la evolución de la capacidad intelectual, lo que es posible que el educando con una discapacidad intelectual tarde más en adquirirlos.

Por tanto, es necesario como explica Euroinnova (2016) alargar el periodo de prácticas manipulativas, visualización de los esquemas, así como de los conceptos claves los cuales son indispensables para la asimilación e interpretación de los ejercicios que conducen a la solución de los problemas planteado. 


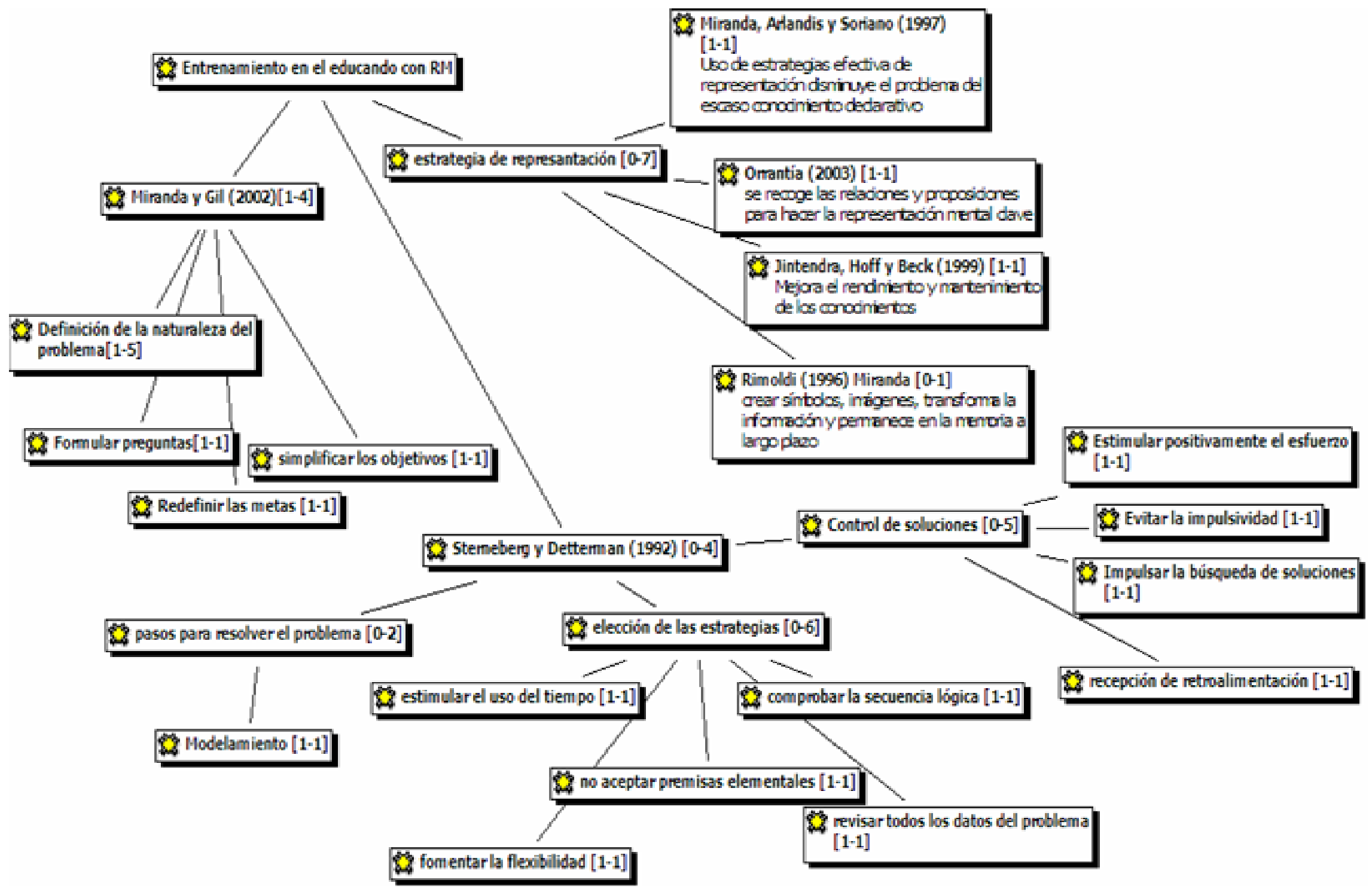

Gráfico 2. Red semántica sobre los procesos cognitivos y la discapacidad intelectual y del desarrollo 
Esta estrategia consiste en la transformación de la información presentada en una forma más fácil de almacenar en el sistema de memoria, e incluye la identificación de las metas y los datos. La representación también ha sido denominada espacio del problema para referirse a las representaciones mentales que los individuos hacen acerca de su estructura y de los hechos, conceptos y relaciones del mismo. (Poggioli, 1989).

\section{CONCLUSIONES}

Con los resultados alcanzados en el análisis se concluye que:

- El aprendizaje de la resolución de problemas puede ser estimulado a través de la aplicación de la psicología de los procesos cognitivos; usando la representación donde se formulan diferentes esquemas mentales que encaminan al educando en es el procedimiento que debe seguir para la solución.

- El organismo humano puede aprender estableciendo los sistemas de relaciones entre los componentes de un problema representándolo de manera sucesiva y simultánea, estos conceptos nacen de la teoría del procesamiento de la información que refiere que los dos modos de procesar la información tienen que ver con las condiciones determinadas por los factores socioculturales, genéticos y las demandas de la tarea.

- La resolución de problemas bajo la psicología de los procesos cognitivos especifica el puente que se hace entre el proceso de enseñanzaaprendizaje y los conocimientos que se desarrollan en otras asignaturas académicas y en la vida cotidiana.

- Al descomponer las particularidades del funcionamiento cognitivo del educando con discapacidad intelectual y del desarrollo desde un modelo de procesamiento de la información, se obtiene tres componentes: simultáneo, sucesivo y planificación, donde su interrelación con la información recogida, le permite conseguir el resultado acertada al problema planteado.

- Al estudiar el proceso cognitivo de resolución de problemas en el educando con discapacidad, se observan ciertos rasgos, como son: la falta de planificación y la ausencia del uso espontáneo de estrategias de almacenamiento, pero cuando se les entrena en el uso de estrategias, muestran facilidad para retener ese aprendizaje y lograr generalizarlo o transferirlo a otras situaciones similares.

- Otro aspecto resaltante es contemplar en la resolución de problemas las funciones ejecutivas del estudiante, Moraine (2014), que consiste en crear imágenes mentales, recopilar información en la mente para desenvolverse en el entorno y conseguir objetivos. Son fundamentales por ejemplo cuando se planifica el día al levantarse por la mañana, pensando qué se tiene que hacer, en qué orden, cuánto tiempo, e incluso si hay que modificar el plan sobre la marcha en caso de que haya algún imprevisto o se necesite realizar alguna nueva tarea con la que no se contaba.

\section{REFERENCIAS}

Asociación Americana de Discapacidades Intelectuales y del Desarrollo (AAIDD) (2011). Discapacidad intelectual. Definición, clasificación y sistemas de apoyo. Traducción de Miguel Ángel Verdugo Alonso. Undécima Edición. Psicología Alianza Editorial. Madrid: España

Andre, T. (1986) Problem solving and Education. En G.D. Phyre \& T. Andre (Comp.), Cognitive classroom Learning. Understanding Thinking and problem solving. New York: Amedemic Press 
Balestrini, M (2003). Estudios documentales, teóricos, análisis del discurso y las historias de vida. Una propuesta metodológica para la elaboración de sus proyectos. Segunda edición. $\mathrm{Bl}$ Consultores Asociados. Servicio Editorial. Venezuela

Barrios de la Puente, J. (2009). Hacia una Educación Inclusiva para Todos. Revista Complutense de Educación Vol. 20 Núm. 1 (2009) 13-31

Benedet, J. (1991). Procesos cognitivos en la deficiencia mental. Concepto, evaluación y bases para la intervención. Madrid: Pirámide

Bermejo, V., \& Rodríguez, P. (1994). Competencia conceptual y de procedimiento: comprensión de la propiedad conmutativa de la adición y estrategias de solución. Estudios de Psicología.51, 3-21

Bermejo, V., \& Rodríguez, P. (1987). Estructura semántica y estrategias infantiles en la resolución de problemas verbales de adición. Infancia y Aprendizaje, 39-40, 71-81.

Bermejo, V., \& Rodríguez, P. (1990). Relevancia de algunos factores en la solución de problemas aditivos. Investigaciones Psicológicas. 8, 23-41. .

Bermejo, V., Lago, M. O., \& Rodríguez, P. (1998) Aprendizaje de la adición y sustracción. Secuenciación de los problemas verbales según su dificultad. Revista de Psicología General y Aplicada, 51, 533-552

Bermejo, V., \& Lago, M. O. (1992). La habilidad de contar: ejecución, comprensión y funcionalidad. Revista de Psicología General y Aplicada, 45, 2, 201-209

Carpenter, T. P., Empson, S. B., \& Jacobs, V. (1995, Noviembre). Integración de la investigación cognitiva con la investigación en el aula: ejemplos de instrucción matemática innovadora. Congreso de Psicología y Educación, Madrid España.

Carpenter, T. P. \& Moser, J.M (1983). The acquisition of addtion and subtraction concepts. En Lesh $R$, \& Landau. $M$, Adquisition of mathematics concepts and processes (p.p. 7-39). London: Academic

Carpenter, T.P.\&Moser,J.M(1982). The development of addition and-subtraction problem-solving skills. En Capenter. T, Moser. J, y Romberg. T, (Editores), Addition and subtraction: a cognitive perspectiva (p.p. 9-24). Hillsdale, New Jersey: Lauwrence Erlbaum Associates, Publisher

Ellis, N. (1963). Memory processes in retardates and normals. Theoretical and empirical considerations. En N. R. Ellis (Dir)

Euroinnova (2016), Manual del alumno. Pedagogía Montessori. Volumen 2. Editorial Euroinnova. Madrid: España

Gallagher, M.L (2001). Helping students with learning disabilities make sense of word problems. Intervention in School and Clinic, 37, 13-18

Gerard, G. (1990). Strategies that learning-disabled students solve verbal mathematical problems. Preventing School Faulure, Fall, 35

Gil, M \& Miranda, A (2002).Las dificultades de aprendizaje de las matemáticas en educación primaria: la resolución de problemas. En Aplicaciones de Intervenciones Pedagógicas. Coordinador Garcia, Jésus. Ediciones Pirámide. España

Gil, M \& Miranda, A (2002). La actuación preventiva en la educación infantil: el concepto de número. En Aplicaciones de Intervenciones Pedagógicas. Coordinador Garcia, Jésus. Ediciones Pirámide. España

Ginsburg, H. (1989). Prólogo. En A. Baroody (Comp.) El pensamiento matemático en los niños. Madrid: Visor: Libros

Greeno, J. G. (1980). Threads in the Theory of knowledge for problem solving. In D. T: Tuma y F. Reif (Eds). Problem solving and education: Issues in Teaching and Learning. (pp. 9-24) Hillsdale, N. J. Erlbaum

Hale, C \& Borkowski, J. (1991). Attention, memory and cognition. En J. Matson, y J Mulick (Eds). Handbook of Mental Retardation. New York: Pergamon Press

Jintendra, A., Hoff, K \& Beck, M (1999). Teaching middle scholl students with learning disabilities to solve word problems using a schema-based approach. Remedial and Special Education, 20, 50-64

Jintendra, A, \& Hoof, K. (1996). The effect of schema-based instruction on mathematical word problem problem solving performance of students with learning disabilities. Journal of Learning Disabilities, 29, 422-431 
Jintendra, A., \& Pin, Y. X. (1997). Mathematical word-problem-solving instruction for students with mild disabilities and students at risk for math failure: a research synthesis. The journal of special education, 30 (4), 412-438

Luria, A. (1963). Psychological studies of mental deficiency in the Soviet Union. En N.R. Ellis (Ed), Handbook of mental deficiency. New York: McGraw-Hill.

Mayer, R. (1986). Capacidades matemáticas. En R. J. Sterberg, Las capacidades humanas. (pp. 165194). Barcelona: Editorial Labor

Miranda, A.; Arlandis, P \& Soriano, M. (1997). Instrucción en estrategias y entrenamiento atribucional: efectos sobre la resolución de problemas y el autoconcepto de los estudiantes con dificultades de aprendizaje. Infancia y Aprendizaje, 80, 37-52

Miranda, C, \& Gil, M; (2002). Las dificultades de Aprendizaje de las matemáticas en educación primaria: el cálculo. En Aplicaciones de Intervención Psicopedagógica. Coordinador Garcia, J. Ediciones Pirámide

Moraine, P. (2014). Las Funciones Ejecutivas del Estudiante. Madrid: Narcea
Polya, G. (1962). Mathematical discovery. New York: John Wiley y Sons

Pozo, J. (2016). Aprender en tiempos revueltos. Madrid Alianza

Puente, A. (1998). Cognición y Aprendizaje. Fundamentos psicológicos. Madrid: Pirámide

Puente, A. (1993). Modelos mentales y habilidades en la solución de problemas aritméticos verbales. Revista de Psicología General y Aplicada.46. (2), 149-160

Rimoldi, H.J. (1996). Estructuras e imágenes en la solución de problemas. Revista de Psicología General y Aplicada, 30, (3), 285-296

Simon, H. (1978). Information-Processing. Theory of human problem solving. En W. K. Estes (Comps), Handbook of Learning and Cognitive processes: vol 5 (pp: 81-96). Aellsdale: N. J : L. E. A

Simon, H. A. (1980) Problem solving in education. En D.T. Tuma \& F. Reif (Comp.) Problem solving and education: Issues in Teaching and research. (pp. 81-96). Hillsdale; N.J.: Erlbaum

Sternberg, R., \& Detterman, D. (1.992). ¿Qué es la Inteligencia? Enfoque actual de su naturaleza y definición. (2a ed.). Madrid: Pirámide 